\title{
THE IMPLEMENTATION OF ITEM IN BOTSWANA
}

\author{
Coach Kereteletswe and Ian Selwood
}

The University of Birmingham, School of Education, Edgbaston, Birmingham, B15 2TT, UK

\begin{abstract}
This paper reports on the implementation of a computer-based system for the management of education in Botswana. The computerisation project began in April 1998 and went live, in the Ministry of Education, on the $3^{\text {rd }}$ May 1999. The rollout to the five Regional Education Offices and the twelve Education Centres was ongoing at the time of research (June-September 2001), and the rollout to the 827 state-owned secondary and primary schools was to follow in the next phase. Botswana, like many developing countries, has an education system that has a highly centralised management structure, with very few management responsibilities devolved from central government. The approach to implementing Information Technology in Educational Management (ITEM) commencing at the Ministry and then rolling out down the system is perhaps unique. These factors therefore accorded the opportunity to study the top-down implementation of a computerised information system in a developing country. This paper briefly describes Botswana and its education system before describing research that analyses the first stages of the implementation of ITEM in Botswana.
\end{abstract}

Key words: Educational management, research, developing country, change management, implementation.

\section{BACKGROUND}

Botswana is a large landlocked Southern African country with an area of 582,000 square kilometres (roughly the size of France). However, the population is demographically small, estimated at 1.7 million people, with almost half its population under the age of 15 years. Unlike most African

The original version of this chapter was revised: The copyright line was incorrect. This has been corrected. The Erratum to this chapter is available at DOI: 10.1007/978-0-387-35689-1_19 
countries, Botswana is culturally homogeneous, and approximately $80 \%$ of the population belong to the same ethnic and linguistic group (MoE 1977). Setswana and English are the official languages with the latter being the most widely used in Government, business and education. In 1966, when Botswana became independent, the country was classified by the United Nations as one of the 25 poorest countries in the World (Jones 1977, Taylor 1992). Since independence, Botswana's economy has been growing rapidly in terms of Gross Domestic Product, and per capita incomes rose from US\$50 in the 1960s to US\$3750 in 1995.

In Botswana, the responsibility for virtually all decision-making concerning staffing, expenditure and curriculum resides with The Ministry of Education (MoE). The MoE has a political head, the Minister of Education, supported by a Permanent Secretary who is assisted by two deputies. The ministry has twelve departments, each headed by a director, and this study focuses on four of these departments - the departments of: Secondary Education (SE), Primary Education (PE), Teacher Training and Development (TTD) and Teaching Service Management (TSM) (see Figure 4-1). TSM, the major focus of the study, is the department responsible for the provision and deployment of teachers to all levels of the education system, in all regions of the country (TSM 2001).

Since independence, Botswana has endeavoured to improve the quality of her education through a number of commissions. The first was 'Education for Kagisano' which led to the adoption of 'The National Policy on Education' (MoE 1977). Initially Botswana opted for 9 years of basic education, but this was later revised to an entitlement for all of 10 years of basic education. This policy led to a rapid expansion of the education system quantitatively; sadly, this was associated with a decline in quality. In 1994, a new education policy 'The Revised National Policy on Education' (RNPE) was adopted (MoE 1994) and this reported that:

"educational development has been characterised by a massive expansion of school places. For example between 1979 and 1991 enrolments in primary schools rose by $91 \%$, in secondary schools by $342 \%$ and at the university by 315\%." (MoE 1994: 3). 


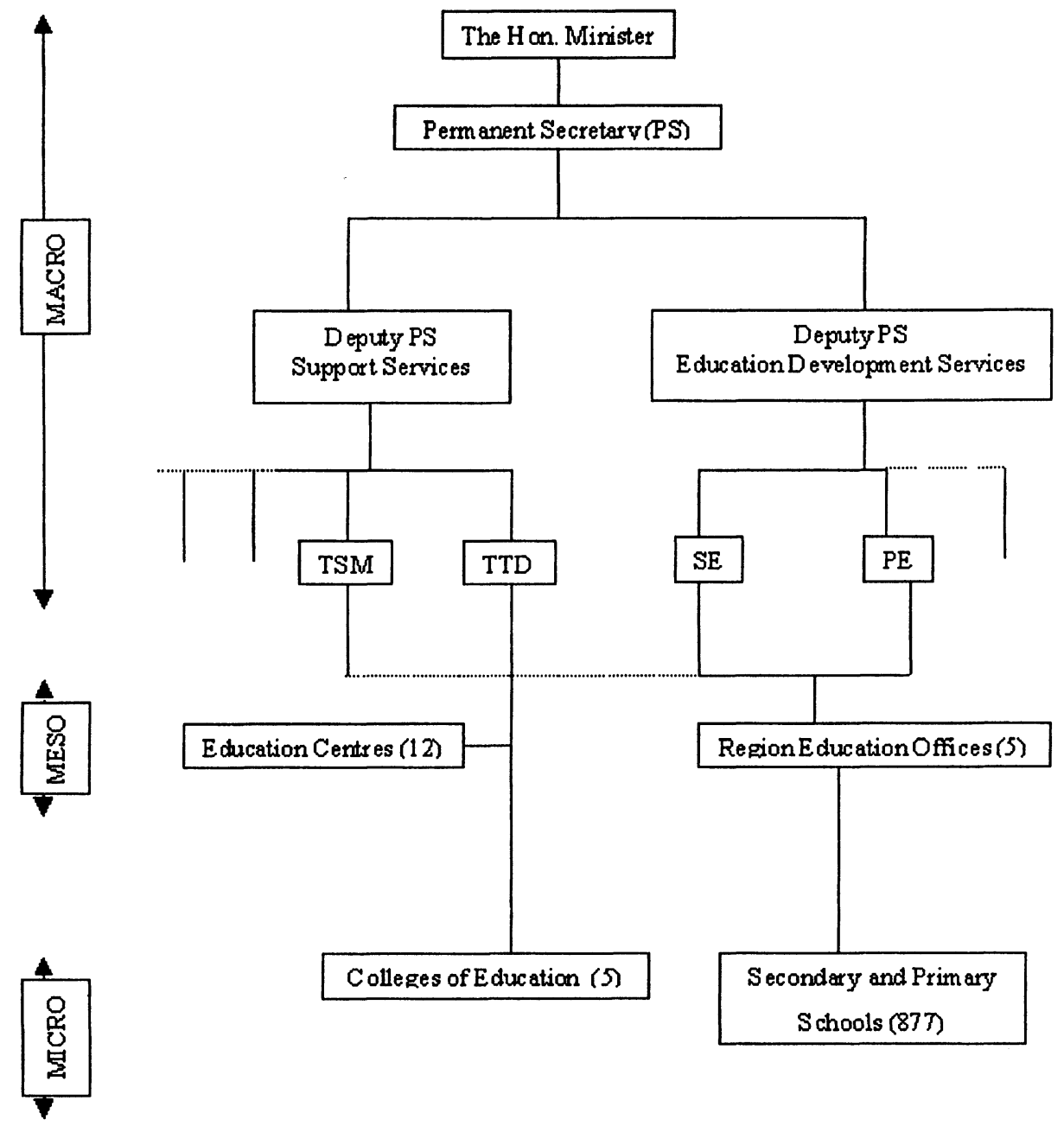

Figure 4-1. Organisation of Education in Botswana (DPSM 1992)

However, research undertaken by the Commission revealed that:

"... academic achievement of standard seven completers is declining. At the Junior Certificate level the pass rate for the Form 2 declined from $85.3 \%$ in 1988 to $80.1 \%$ in 1991 and for Cambridge (Certificate) from 79.3 to $69.9 \%$ in the same period." (MoE 1994: 3).

This massive expansion in schools places demanded a corresponding substantial increase in the teaching workforce. In an effort to improve the management of education, the Government of Botswana conducted a review of the organisation and methods of the MoE (DPSM 1992). The Directorate 
of Public Service Management (DPSM) that carried out the review and reported that:

“........serious organisational problems, including manpower being inexperienced in the overall functioning of the (then) Unified Teaching Service." (DPSM 1992: 3)

Furthermore, the review showed that it was difficult if not impossible to obtain a clear and comprehensive written statement describing the objectives of the MoE at the national level. Additionally, there was no clear statement of the major functions within the MoE. The review recommended some major restructuring in the MoE (DPSM 1992). However, in spite of the restructuring, the MoE indicated in 1994 the need for effective management of the education system, stating that:

"The increase in the number and spread of educational institutions in the country, especially at primary and secondary levels, presently poses problems of effective administration in view of the centralised nature of the management structure." (MoE 1994: 4).

The RNPE of 1994 further observed that:

"The success of any education system depends largely on teachers. They are the catalyst of the learning process and on them mainly rests the whole system. They are therefore crucial in the strategy to achieve a more effective and responsive system." (MoE 1994: 4).

Therefore, the effective management of the teaching force was seen as paramount to expanding education and maintaining quality. However, in spite of the reorganisation of the Department of Teaching Service Management (TSM), problems persisted with regard to the service delivery of the department. This was in part due to the manual system in which more than 26,000 teacher records were stored. Additionally, the decline in quality in education had been largely attributed to the lack of resources (i.e., trained teachers, classrooms, science laboratories and equipment).

\section{STATEMENT OF THE PROBLEM}

In the TSM, manual processing of large volumes of information was strenuous and time consuming, resulting in inefficiency and poor accountability of managers. Often, it took a very long time for new teachers to get their salary, teachers were sometimes not paid for up to 6 months. 
In summary the factors viewed as inhibiting the performance of TSM were:

- Inadequate up-to-date management information

- Lack of visibility of the daily transactions

- Large volumes of paperwork handled daily, which resulted in the misplacement of files and unavailability of data to staff for unacceptable periods.

- Lack of timescales and resources needed to generate management and statistical reports for $\mathrm{MoE}$ and/or other interested parties.

- Data available from other systems (e.g. payroll) only provided current staffing information without history or planning capabilities.

- Growing concern over the accuracy and currency of the paper files for teachers within TSM

- There was lack of feedback from other stakeholders involved in the management and administration of teachers (DPSM 1996).

In response to the above problems and the information explosion, TSM was charged with responsibility of spearheading the implementation of a multimillion-pula ( $£ 1=\mathrm{P} 8.86)$ computerisation project. The project introduced by the $\mathrm{MoE}$ was to tailor the "Infinium" software (the package chosen by the government for managing human resources) and to develop an integrated computer network linking the administrative parts of the education system at the macro, meso and micro levels shown in Figure 4-1.

\subsection{Research Questions}

The study reported in this paper sought to answer the following principal research question: Why and how was ITEM implemented in the department of Teaching Service Management (TSM) in Botswana? This principal research question was broken down into five subsidiary interrelated research questions:

1. What was the purpose of introducing the Infinium system in the department of TSM?

2. What were the stages/phases taken in implementing the Infinium system in the department of TSM?

3. To what extent were the users involved in the adoption and implementation of Infinium in the department of TSM?

4. Was Infinium tailored to meet the needs of the organisation?

5. Were there any modifications in the user systems resulting from the introduction of Infinium? 


\subsection{Theoretical Framework}

The study reported in this paper analyses the implementation of ITEM using a combination of three perspectives as a theoretical framework. They are Fullan's (1991) management of change theories, Fung's (1995) Six-A Process Model and Riggs' (1964) Prismatic Model.

Fullan (1991) viewed change as a four-stage process from initiation, to implementation, continuation and outcome. However, the Six-A model by Fung (1995) provides an elaborated scenario of Fullan. The model comprise a six-stage process from awareness, to attitude formation, adoption, adaptation, action and application hence the six A's.

Riggs (1964) theory of the prismatic society is based on the analogy of white light ray passing through the prism emerging diffracted into the seven colours of the rainbow spectrum. Within the prism, there is a stage where the diffraction starts but remains incomplete. This stage represents both elements of the traditional, fused (white light) type of organisation and elements of the structurally differentiated (diffused light) of 'modern' societies. Riggs was primarily concerned with the analysis of the workings of public institutions of central government and public administration in developing countries. However, Harber and Davies (1997) state that Riggs' theory is a useful explanatory tool for understanding how education departments and schools operate as organisations in developing countries. In essence, the prismatic model is a useful theory in providing the management context in which change is to take place in developing societies.

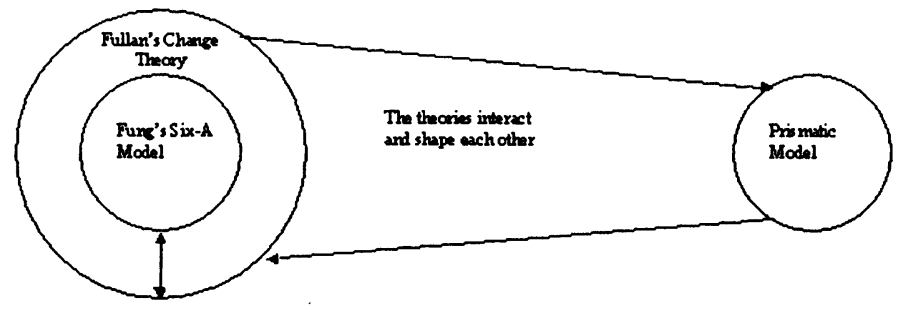

Figure 4-2. $\mathrm{F}^{2} \mathrm{R}$ Model

Figure 4-2 shows the diagrammatic representation of a bonding of the three theoretical perspectives. The model consists of concentric circles showing the Six-A Process model contained in Fullan's (1991) Theory of Change connected by a bi-directional arrow. The prismatic model is linked to the concentric circles by two-way arrows. These two-way arrows imply that interaction between the perspectives is not a unidirectional process, but 
rather one in which events at one perspective feedback to alter decisions from the previous model in a phenomenological way. These then proceed to work their way through in an interactive way with a view to emphasising the meaning of the innovation to the concerned parties.

Fullan (1991) comments that the intention of educational innovation is to assist schools and education departments to accomplish their goals more effectively by replacing some structures, programmes and/or practices with better ones. The notion of replacing existing system with better ones is controversial in developing countries. Riggs (1964) observed that in a prismatic society it is difficult to replace the existing (old) systems with the new. Instead, there is a tendency for the new practices to partially displace the old, instead of replacing them. Often, there are problems stemming from the co-existence of the heterogeneous mixture of the old and the new.

Fung (1995) stressed the need for users to participate and be involved in the adoption of innovations for the purposes of ownership and meaningful contribution to the overall design and development of the solution. This is also emphasised in the contemporary literature on ITEM (Fung and Visscher 2001), which asserts that involvement of users avoids ill-conceived designs, and encourages commitment to the new system. Also, the ETHICS approach (Mumford 1983, 1995) is one that recognises the interplay between technology and people, resulting in work systems that are both technically sound and have social characteristics, and this leads to high job satisfaction and creates high quality products.

The $F^{2} R$ model developed for this research not only considers the change process as seen in developed countries but also the tensions between modern and traditional societies.

\section{METHODOLOGY}

According to information provided by the department of TSM, the Infinium System was used by 61 employees in TSM and had been rolled out to three other supervisory departments at the MoE headquarters (SE, PE and TTD). Although the other supervisory departments had Infinium installed, they were not using it and as such could not respond to the questionnaire. The rollout to the five Regional Education Offices (REO) and the twelve Education Centres (ED) was ongoing at the time of research; thus, these were also excluded from this evaluation. Therefore, the questionnaire was administered to the 61 users in TSM.

A total of $58(95 \%)$ users responded to the survey. In addition to the questionnaire, 5 managers, 1 middle manager and 2 technical staff were interviewed. In this paper, the findings will be predominantly based on the 
analysis of data derived from the interviews, supplemented with some initial findings from the survey. However, as analysis of the questionnaires was not complete at the time of writing this paper, quantitative data will be reported more fully at a later date.

\section{DATA ANALYSIS AND RESULTS}

\subsection{Purpose for the introduction of Infinium System MoE}

The number of teachers employed in Botswana had increased from 1,717 (1965) to approximately $(26,000)$ in 2001 . The manual system was proving inadequate in coping with problems of an information explosion of this magnitude. Hence, the prime purpose for introducing Infinium was to manage the personnel records of teachers. The increase in information was however twofold: first, increase in teachers and second, increase in policies generated by TSM to manage the teachers.

Users' perceptions on the need to change were investigated and Table 4-1 shows the results of this. $75 \%$ of the respondents firmly agreed with the statement that the need to introduce Infinium HR was 'to improve the record keeping system' and only $2 \%$ disagreed.

Table 4-1. Users' response on the need to introduce the Infinium System

\begin{tabular}{llll}
\hline N=58 & $\begin{array}{l}\text { Firmly } \\
\text { Disagree }\end{array}$ & Uncertain & $\begin{array}{l}\text { Firmly } \\
\text { Agree }\end{array}$ \\
\hline To improve record keeping system & $2 \%$ & $23 \%$ & $75 \%$ \\
To improve management of information & $2 \%$ & $27 \%$ & $71 \%$ \\
$\begin{array}{l}\text { To improve service delivery in the management of } \\
\text { education }\end{array}$ & $4 \%$ & $33 \%$ & $63 \%$ \\
$\begin{array}{l}\text { To improve decision making process } \\
\text { To improve understanding of management issues }\end{array}$ & $5 \%$ & $33 \%$ & $62 \%$ \\
\hline
\end{tabular}

It had also been observed that documents were getting 'lost'. Generally, the accidental loss of documents by error may imply improper filing systems in the department. However, some documents appeared to be lost deliberately and this has other implications. Harber and Davies (1997), Reilly (1987), and Riggs (1964) all note that lack of up-to-date data and ineffective personnel record systems can lead to anti-social acts. Hence, the purpose of introducing the Infinium system was also to end the 'loss' of 
records. The purpose for the change therefore, has this double-edged meaning in the prismatic society.

The respondents' perceptions on the need to implement the Infinium System seem to point to the need for change relating to three of the four purposes for introducing IT detailed by Cash et al. (1994) i.e. automating, informating and communicating.

\subsection{Choosing the System, Managing the Project, and Modifying Infinium}

\subsubsection{Origination and Policy Implementation}

Interviews revealed that there had been three feasibility studies conducted in 1986, 1988 and in 1993 that examined the case for introducing IT into the Government of Botswana. Based on these studies a Statement of User Requirements (SOUR) was developed. A committee consisting of: The Manager of Government Computer Bureau (GCB), Deputy Permanent Secretary (DPS) Ministry of Home Affairs, DPS Ministry of Finance and Development Planning, a Representative from MoE and others, was set up to consider computerisation of the government departments. Thus, decisionmaking was at the apex of the government's administrative hierarchy. Based on the SOUR the committee selected and purchased an Infinium software license and it became government policy for its departments and agencies, involved in the management of human resource, to adopt Infinium. The MoE charged TSM with the responsibility to implement the strategy in all departments involved in the management and administration of teachers. The TSM department subsequently formed a Project Board (PB) comprising the top managers of the stakeholder departments responsible for the management and administration of teachers. The purpose of the PB was to oversee and review the overall progress of implementation, and decide whether the project should continue after each implementation stage. To manage the day-to-day implementation of the Infinium project, TSM employed an Implementation Manager (IM), supported by an Infinium consultant based in Botswana, and one other person. This group became the Change Facilitator System (CFS).

\subsubsection{Involvement and Participation of Users and User Departments}

Interview data confirmed that the user departments (stakeholders) were not involved in either the decision to computerise or the decision to adopt the Infinium strategy at TSM. A nineteen-member application team (AT) was 
set up comprising the Director and assistant director of TSM and approximately three representatives from each division of TSM. The team was formed after the realisation that the SSADM could not supply adequate information with respect to procedures and practice used in the manual system (see 4.2.3 below). The application team participated in defining the user requirements, the new system, and documenting and compiling the procedure manuals.

\subsubsection{System Design}

Interviews revealed that a Structured System Analysis and Development Methodology (SSADM) was used initially and had included a situation analysis, requirement analysis and definition of requirements, and the design and physical tailoring of the system. Infinium Software comprises of nine modules, however only two of the nine were implemented. These were Infinium Human Resource (HR) and Training (TR) Modules. The initial tailoring of the new system was based on the SSADM and this according to the technical experts did not satisfy the systems tradition cycle. In part, the reason provided for this were inconsistencies between information collected from TSM employees and the actual situation. There had been no documentation on how the users worked in the manual system and there were differences in the interpretation of their functions. The technical experts were therefore dependent on 'good guesses', interviewing of users, and data collected from documents that did not reflect the reality on how users worked. This situation reflects Riggs' (1964) view that, in a prismatic society, roles of managers are fused and often not clearly outlined or defined, resulting in formalistic structures that do not reflect the true organisational function. Consequently, the results obtained from the evaluation of such organisations result in system design failure.

As a result of the SSADM failure, key people in the management of education (at macro level), the AT, were brought in to advise on further customisation of the Infinium Software. There was, therefore, a need to include in the design strategy those users involved in the management of education in TSM. In this way, their involvement may maximise human gains while at the same time achieving organisational and technical excellence. However, it was reported by a member of the CFS that '...based on a number of meetings and telling application team members what to do we defined some procedures .... and tailored the core HR system.' This notion reflects lack of objectivity on the part of the CFS and suggests they pushed their own agenda on the tailoring of the solution, and did not really consult the users. 


\subsection{Implementation of Infinium System}

\subsubsection{Awareness, Attitude Formation and User Training and Support}

In each category of the questionnaire concerning CFS performance (Table 4-2) the majority of users were 'uncertain' that the CFS did enough in terms of raising awareness, communicating and transmitting knowledge with a small percentage of them firmly disagreeing. Also, only $19 \%$ firmly agreed that the CFS trained them sufficiently with $32 \%$ disagreeing. Moreover, it was reported that after training some users could not have hands-on practice because computers were not installed in their offices. However, $81 \%$ of the users had prior computer experience before the introduction of Infinium System in April 1998

Table -2. User perception on the performance of CFS

\begin{tabular}{llll}
\hline N=58) & $\begin{array}{l}\text { Firmly } \\
\text { Disagree }\end{array}$ & Uncertain & $\begin{array}{l}\text { Firmly } \\
\text { Agree }\end{array}$ \\
\hline $\begin{array}{l}\text { The CFS raised my level of computer awareness } \\
\text { sufficiently }\end{array}$ & $12 \%$ & $52 \%$ & $37 \%$ \\
The CFS transmitted knowledge clearly & $11 \%$ & $48 \%$ & $41 \%$ \\
The CFS communicated information well & $25 \%$ & $33 \%$ & $31 \%$ \\
The CFS trained me sufficiently & $32 \%$ & $49 \%$ & $19 \%$ \\
\hline
\end{tabular}

\subsubsection{Procurement of Equipment and Installation}

The procurement of much equipment was in October 1998, ahead of the design stage. The equipment was supplied and installed by IBM Botswana. Infinium was installed on an AS400 server that was perceived to have immense stability and the capacity to handle the data.

\subsubsection{Government Data Network (GDN)}

The GDN was in place at the time Infinium HR was being tailored at TSM. GDN is an electronic communication system for managers only. It therefore, has some serious implications with regard to the rollout of Infinium to schools, as teachers are not considered to be managers. It was reported that due to this constraint an Education Data Network (EDN) was to be developed. 


\subsubsection{Pilot Project and Rollout to TSM and user Departments (Macro level)}

The 19 members of the application team piloted the project. However, as mentioned earlier the 19 members of this team belonged to only the six divisions of TSM. Interviews revealed that the pilot was successful and the project was rolled out to other users in TSM as well as other user departments involved in the administration and management of teachers in the MoE (SE, PE, TTD) and the Department of Planning Research and Statistic (DPRS).

\subsubsection{Live running at TSM}

It was reported that the system went live on the $3^{\text {rd }}$ May 1999 , and it was on time.

\subsubsection{Modification of Organisation and Methods}

The majority of the informants (95\%) agreed that 'there was no significant change in the organisation and methods'. There were, however minor changes reported on work habits and this was attributed to data capture. It was further suggested that there was instability in tasks and procedures at macro level, stemming from decentralisation of functions to the meso level. It was reported that lack of modification to procedures and conditions of service resulted in incompatibilities in the new ways of working.

\subsubsection{Rollout REO and ED and Implementation Constraints}

At the time of writing an $80 \%$ of rollout to the ED had been achieved. However, there were constraints in rolling out the project to REOs stemming from policy interpretation and implementation, resulting from decentralisation of the functions of the MoE. The other constraints reported were: shortage of telecommunication lines, acute shortage of resources, lack of electricity in some parts of the country, geographical size of the country and lack of skilled computer personnel. 


\section{CONCLUSIONS}

Botswana is a developing country with a highly centralised system for managing education. Due to the rapid expansion of the education system, the manual system of managing the teaching workforce was not working efficiently or effectively. Initial analysis of data collected concerning the adoption and implementation of ITEM has been presented and shows that:

- Users perceptions with respect to the need for implementing ITEM were mainly concerned with the need to improve record keeping and the management of information. With concerns over 'loss' of records being highlighted.

- The software to be used in the project (Infinium) was chosen by a Governmental Committee, which was concerned with the management of human resources in all areas of government, not just education. Potential user departments in the MoE were not consulted on the decision to computerise or the choice of software. However, Fung (1995) and Mumford (1995) had both noted the need for user involvement at all stages of implementation.

- The Department of Teaching Service Management (TSM) were chosen to lead the implementation of the Infinium System in the MoE and TSM set up a Project Board (PB) to oversee the project and a Change Facilitator System (CFS) to manage the day to day implementation.

- SSADM proved to be inadequate in revealing the complexities of the manual system due to a high degree of formalism in the TSM (resulting from latent functions of managers)(Riggs 1964). This resulted in an application team of stakeholders being set up under the Director of TSM to advise the CFS. However, the attitude of the CFS appears to have been that 'they knew best'.

- Some incompatibilities were reported in the new ways of working. However, users reported that there had been no significant changes in how they worked i.e. they felt that manual procedures had been computerised. This reflects Riggs (1964) assertion that, in a prismatic society, due to the heterogeneous mixture of old and new, the new system does not replace, but instead displaces the old. Fullan's (1991) view that education departments accomplish their goals more effectively by replacing structures and programmes with better ones may not be entirely appropriate for a prismatic society.

- The users were predominately unconvinced with the performance of the CFS, with respect to various aspects such as: keeping users informed, awareness raising, and training supplied.

- Problems in rolling out to EDs and REOs were reported. 
Understanding and managing change are dominant themes in management today. The change models proposed and used in developed countries for IT systems (i.e. Fung 1995 and Fullan 1991) may not be entirely appropriate for developing countries/prismatic societies. Therefore, another model, the $F^{2} R$ process model, was developed drawing on the work of Riggs (1964) and others with experience of developing countries, together with the work of Fung (1995) and Fullan (1991). Even after preliminary analysis of the first stages of this ongoing research project, this model seems to be useful in confronting the complexities of change in transitional societies in a phenomenological way.

\section{REFERENCES}

Cash, C.I, Jr., Robert G.E., Nitin, N. and Richard L.N. (1994). Building the Information-Age Organisation: Structure, Control, and Information Technologies. R.R. Donnelly \& Sons Company, London.

Danzin, A. (1983). The nature of New of Technology, in New Office Technology: Human and organisational aspects. H.J. Otway and M. Peltu (eds). Frances Pinter Ltd, London.

DPSM (1996). Strategy Statement; Computerisation of Personnel Information. Unpublished

DPSM (1992). Report on the Organisation Review Ministry of Education. Botswana Government Printers, Gaborone.

Fullan, M. (with Stiegelbauer) (1991). The New Meaning of Education Change. Cassell, London.

Fung, A.C.W. (1995). Managing Change in "ITEM", in Information Technology in Educational Management. B. Barta, M. Telem and Y. Gev (Eds.). Chapman \& Hall, London.

Fung A.C.W and Visscher, A.J. (2001). Computer-Assisted School Information Systems: The concepts, intended benefits, and stages of development, in Information Technology in Educational Managemnt; Synthesis of Experience, Research and Future Perspectives of Computer-Assisted School Information Systems (A.J. Visscher, P. Wild and A.C.W. Fung (eds). Kluwer Academic Publishers, London.

Harber, C and Davies L. (1997). School Management and Effectiveness in Developing Countries: The Post-Bureaucratic School. Cassell, London.

Jones, D (1997). Aid and Development in Southern Africa, Croom Helm, London.

MoE (1977). Education For Kagisano, Report of the National Commission on Education. Government Printer, Gaborone.

MoE (1994). The Revised National Policy on Education (RNPE). Government Printer, Gaborone.

MoE (1999). Excellence in Education for the New Millennium: A Comprehensive Report on the Implementation of the Revised National Policy on Education. Government Printer, Gaborone.

Mumford, E. (1983). Successful Systems Design, in, New Office Technology: Human and organisational aspect. H.J. Otway and M. Peltu (eds). Frances Pinter Ltd, London.

Mumford, E (1995). Effective System Design and Requirement Analysis; The ETHICS Approach. Macmillan Press Ltd, London. 
Reilly, W. (1987). Management and training for development: the Hombe thesis, Public Administration and Development, 2, 25-42.

Riggs Fred, W. (1964).Administration in Developing Countries Countries: The Theory of Prismatic Society. Houghton Mifflin, Boston.

Taylor, D.C. (1992). Alternative Models of Secondary Schooling in Botswana, Department of Educational Studies, (PhD thesis, University of Manchester).

TSM (2001). Department of Teaching Service Management Strategic Plan. Unpublished 